\title{
Timely Access to Maternal, Neonatal and Child Healthcare for rural communities in Rwanda: Job satisfaction of Community Health Workers delivering Community Based Maternal, Newborn and Child Healthcare
}

Jean Bosco BIGIRIMANA ( $\sim$ geobig1@yahoo.fr)

University of Rwanda College of Medicine and Health Sciences Huye https://orcid.org/0000-0003-3132-1408

Isaac Luginaah

Western University

Research

Keywords: Maternal Health, Child Health, Community Health Worker, Rwanda

Posted Date: July 21st, 2020

DOl: https://doi.org/10.21203/rs.3.rs-44141/v1

License: (c) (i) This work is licensed under a Creative Commons Attribution 4.0 International License. Read Full License 


\section{Abstract \\ Background}

In Rwanda, although there has been progressing in health care delivery as expressed in the reduction in maternal and child mortality, rates are still high and geographically variable. For the improvement of equitable access to health services for maternal, newborn and child healthcare (MNCH), community-based maternal, newborn and child healthcare $(\mathrm{CBMNCH})$ depends on the use of "community health workers" (CHWs). However, the CHW program faces challenges that disrupt the quality delivery of a full package of services. Yet little is known about the satisfaction of $\mathrm{CHWs}$ in delivering $\mathrm{CBMNCH}$.

\section{Methods}

This quantitative cross-sectional study involved a survey of 500 sampled $\mathrm{CHWs}$ delivered $\mathrm{CBMNCH}$ in three selected rural districts of the southern province, Rwanda. Ordinal regression was used to examine the determinants of CHW' job satisfaction.

\section{Results}

Multivariate analysis shows that the determinants of job satisfaction were motivation $(\mathrm{OR}=8.59, \mathrm{p}<0.001)$, formal training in $\mathrm{CBMNCH}(\mathrm{OR}=2.24, \mathrm{p}<0.05)$, individual supervision $(\mathrm{OR}=6.19, \mathrm{p}<0.001)$, and peer support $(\mathrm{OR}=2.66, \mathrm{p}<0.01)$, knowledge about $\mathrm{CBMNCH}(\mathrm{OR}=0.51, \mathrm{p}<0.05)$, access to essential materials $(O R=0.32, p<0.05)$, and incentives $(O R=0.53(p<0.01)$.

\section{Conclusion}

The findings indicated that the managers of $\mathrm{CHW}$ programs and other stakeholders need to improve the working conditions of $\mathrm{CHWs}$ to enhance their job satisfaction, to enable the effective provision of $\mathrm{CBMNCH}$.

\section{Background}

Poor access to health care services are resulting in high maternal, neonatal, and child mortality and morbidity, especially in middle and low-income countries like Rwanda ${ }^{1}$. Besides, inequitable access to health care services partly explains the disparity in a rural-urban dichotomy in morbidity and mortality in many countries $^{2,3}$. Residents in urban areas tend to have improved health outcomes compared to their counterparts in rural communities ${ }^{2,3}$. In several parts of the developing world, there is a deficiency of skilled health professionals. For instance, sub-Saharan Africa remains below the WHO recommended a limit of 2.3 medical doctors, midwives, and nurses, per thousand individuals ${ }^{4}$. Medical doctors are particularly unevenly distributed among urban and rural communities, with deficiencies being considerably more intense in rural communities ${ }^{4}$. In response, CHWs are being depended upon in some countries around the world to address the issue of deficiency health providers by enhancing the provision of primary health care services and promoting health in rural settings or underserved communities ${ }^{5,6}$. The concept of universal health coverage as espoused by the Alma Atta Commission, and subsequently adopted by the WHO is well placed to reduce inequalities in health access ${ }^{6}$. Some countries are endeavouring to close the healthcare gap through universal health coverage, which guarantees reliable and timely access to improved health access regardless of geography and socioeconomic circumstances ${ }^{7}$. It has, therefore, been argued that enhancing equitable access to quality medical services, needs global and national investments that bring health care services closer to those in most need $^{8}$.

In line with the need to improve universal health coverage to deprived communities, the role of CHWs in rural areas in developing countries cannot be overemphasized. A significant priority in health policy is that essential health care services should be accessible geographically: close to where individuals live and work ${ }^{8}$. CHWs are mostly residents in these rural communities. Therefore, the decentralization of healthcare services to remote and rural settings through CHWs has the advantage of geographical proximity and readily accessible within rural settings which also helps bridge socio-cultural and linguistic barriers to health care delivery ${ }^{9,10}$. In a meta-analysis of maternal and child health by Kassebaum et al. ${ }^{11}$, explained the positive impact of $\mathrm{CHWs}$ on reducing maternal and child mortality between 1990-2003 in varying contexts. However, although child mortality reduced about half since the 1990s, and maternal mortality dropped $1.3 \%$ every year since $1990^{11}$; still over 17,000 children are reported to die annually from preventable causes ${ }^{12}$. Stillbirth rates have not significantly changed, and many women are losing their lives due to perinatal-related complications ${ }^{12}$.

In Rwanda, a country known as "the land of a thousand hills," in Eastern Africa on a highland plateau averaging 1,200 to 2,000 m in elevation, the concept of $\mathrm{CHWs}$ is not new. With a commitment to provide universal healthcare as part of its Vision 2020 Strategy, the Rwandan government has implemented a national CHWs program since 2007 as a bridge between local communities and the health care system ${ }^{13}$. Each village (around $100-250$ family units) has one CHW (female), called an "ASM" (Animatrice de santé Maternelle), explicitly focused on follow up of women during pregnancy and after birth, and newborn. They provide Community-Based Maternal, Neonatal, and Child healthcare $(\mathrm{CBMNCH})^{14}$.

Although there has been some progress in health care delivery as expressed in the reduction in maternal and child mortality, rates are still high and geographical variables ${ }^{15,16}$. According to the recent Rwanda Demographic and Health Survey 2014-2015, the annual number of maternal deaths per 100,000 women ages $15-49$, was 210 . The maternal death rate accounted for $15 \%$ of all deaths to women age $15-49$. In other words, about 1 in 6 Rwandan women who died in the five years preceding the DHS-2014/2015 died because of pregnancy or pregnancy-related causes. Overall, the infant mortality rate is 32 per Loading [MathJax]/jax/output/CommonHTML/jax.js s are 50 per 1,000 live births ${ }^{15}$. 
Since its inception, community-based interventions have been generally seen to have fundamentally contributed towards current health achievements in Rwanda ${ }^{17}$. However, in the same way as other African nations, the CHWs program in Rwanda still faces huge difficulties that upset the delivery of the quality of the comprehensive package of services. These difficulties extend from the low limit capacity of CHWs to insufficient resources to sustain routine community health activities ${ }^{17}$. Based on this background, to strengthen its CHWs program, Rwanda Ministry of Health in partnership with Western Ontario University introduced in 2016 the "Training, Support, Access Model" (TSAM) project in the six districts with high MNCH needs amongst others include Rulindo, Gakenke, and Gicumbi in the northern province and Muhanga, Ruhango and Gisagara in the southern province. One of the key objectives of TSAM is to improve $\mathrm{MNCH}$ through community-based interventions using appropriately trained, mentored, and supported $\mathrm{CHWs}^{18}$. This project has implemented in the northern province and is now scaling up in the southern province. Unfortunately, there is little baseline knowledge about CHWs jobsatiaction $\in$ theprovisionofCBMNCH, $\in f$ or mationtwodberequiredbef or eTSAMs $\int$ ervention $\rightarrow \subset$ sequentlyexa min etheimpactmac

job satisfaction prior to intervention in southern province.

\section{Methods}

The study aimed to provide insight into the satisfaction of $\mathrm{CHWs}$ in the provision of $\mathrm{CBMNCH}$ for timely access to maternal, neonatal, and child healthcare in rural communities, Rwanda. The quantitative cross-sectional study was conducted in three selected districts in the southern province including Gisagara, Ruhango, and Muhanga district (working area of TSAM in the south). The study population comprised CHWs delivering CBMNCH within study areas. With the collaboration between the TSAM project and MoH Rwanda, through Rwanda Biomedical Centre (RBC), the sampling frame was obtained from the RapidSMS database. At the time of the survey, the database included $1388 \mathrm{CHWs}$ who were actively providing $\mathrm{CBMNCH}$ in the three study districts. With a confidence level of $95 \%$ and a error probability, 0.05 applied to the population of $1388 \mathrm{CHWs}$, a sample size of $301 \mathrm{CHWs}$ was calculated as the minimum sample threshold for unbiased findings for this study. Even though the estimated minimum sample size was 301 , we oversampled by 200 to give the sample size more power, therefore, a sample of $500 \mathrm{CHWs}$ was used for this study. Because the population size was not equal in each district, at the district level, the sample size was calculated based on district proportionate allocation sampling technique, "probability proportional to size"19.

Systematic random sampling was used to select the study sample from the total population of $\mathrm{CHWs}^{19}$. For data collection, a comprehensive questionnaire for CHWs was developed. This questionnaire was designed from previous $\mathrm{CHW}$ studies in Rwanda and elsewhere and it is, therefore, not a standardized instrument, but it was presented to the team of TSAM experts to discover whether the content is relevant in comparison with the context to ensure its content validity. Then, the research was presented to two Ethics Committees (Western University and the University of Rwanda) for approval. Participation in the research was voluntary. Thus, potential participants had to sign a consent form. The survey was conducted from June 2019 to September 2019.

Job satisfaction is a dependent variable. The Cronbach's alpha was used to generate satisfaction scales by aggregating questions which were asked CHWs to rate their satisfaction on the job as maternal health service providers in rural communities. Scores to these questions were estimated based Likert scale, (5) strongly agree, (4) agree, (3) neutral, (2) disagree, and (1) strongly disagree.

Drawing insights from the literature on satisfaction in health service research ${ }^{20-22}$, we introduced two sets of explanatory variables, namely structural and individual-level factors. Structural factors included CHW's motivation ( 1 = low; 2 = Middle; 3 = high), knowledge level CHW (1 = Low; 2 = Middle; 3 = High), amount of supervision received from a health centre ( $1=$ never; $2=$ Once a year; $3=$ Few times a year; $4=$ Once a month), formal training on $\mathrm{CBMNCH}(1=$ no; 2 =yes), peer support ( 1 = no; 2 =yes), access to assessment tools ( 1 = all are available; 2 = few are missing; $3=$ many are missing; 4 = All are missing), average time spent to travel to the health centre ( $1=$ Less than 60 minutes; $2=60-120$ minutes; $3=$ more than 120 minutes), number of households $\mathrm{CHW}$ is responsible for ( 1 = less than 125 households; $2=125-160$ households; $3=160-200$ households; $4=$ more than 200 households), the average number of clients served in a month ( $1=$ less than 14 clients; $2=14-20$ clients; $3=$ more than 20 clients), years of experience $(1=0-3$ years; $2=4-6$ years; $3=7-9$ years; $4=10$ years and above years), and received in-kind payment for $\mathrm{CHWs}$ services $(1=$ yes; $2=$ no), membership in Profitable cooperatives $(1=$ yes; $2=$ no $)$. For individual-level factors, we included age ( $1=35$ and below; $2=36-49 ; 3=50$ and above), marital status ( $1=$ married; $2=$ other $)$, level of e3ducation ( $1=$ primary; 2 = above primary), occupation ( 1 = smallholder $/$ non-professional farming; 2 = other), household size ( $1=$ less than 5 members; $2=5-7$ members; $3=$ 8 members and above), and socioeconomic status (Ubudehe category) ( $1=$ category $1 ; 2=$ category $2 ; 3=$ category 3 ). According to the Rwandan Ubedehe categorization, category 1 comprises people with no means to own or rent homes of their own and can hardly put food on the table, the second category comprises people who have limited part-time jobs and either own cheap houses or can pay rent, the third category comprises people who do not need help from the Government for survival, and the fourth category comprises people deemed rich such as government officials from the level of director upwards, and large business owners ${ }^{23}$.

Regarding data analysis, we employed univariate, bivariate, and multivariate analyses to understand the factors associated with job satisfaction among CHWs. While our dependent variable (job satisfaction) is ordinally corded ( $1=$ Low; 2 = Middle; $3=$ High), therefore, we em0ployed the ordinal logistic regression, which is suitable for an ordered dependent variable. Models were built sequentially. We accounted for structural variables in Model 1 and individual-level variables in Model 2. Findings were reported in odds ratios (ORs) where ORs larger than 1 indicate higher odds of being satisfied on the job, while ORs smaller than 1 indicates lower odds of being satisfied.

\section{Results}

\section{Univariate}

Table 1 shows findings from univariate analysis. In terms of job satisfaction, we found that $35 \%, 31 \%$ and $34 \%$ of CHWs were highly, moderately, and lowly patinfind mannativalue in tarmn af inh narfarmance, 32.2\%, 35.2, and 32.6\% of CHWs reported high, moderate, and low job performance, respectively. Nearly
Loading [MathJax]/jax/output/CommonHTML/jax.js 
half $(47.8 \%)$ of $\mathrm{CHWs}$ were highly motivated. Also, $35.2 \%$ of surveyed $\mathrm{CHWs}$ had high knowledge about $\mathrm{MNCH}, 34.6 \%$ of them had moderate, and $30.2 \%$ of them had low knowledge. $24.2 \%$ of $\mathrm{CHWs}$ did not receive any individual supervision from the $\mathrm{HC}$ since they started to work as $\mathrm{CHW}$, while $46.6 \%$ of $\mathrm{CHWs}$ receiving individual supervision at least once a year. Besides, $59.8 \%$ of $\mathrm{CHWs}$ reported that they have never received feedback for patients transferred to a Health Center. In terms of training, $73.8 \%$ of $\mathrm{CHWs}$ received formal training in $\mathrm{CBMNCH} ; 58.2 \%$ of them received formal training before working as $\mathrm{CHWs}$. There was a good collaboration among $\mathrm{CHWs}$, with $89 \%$ of them reporting having received peer support. Regarding the availability of materials, only $21.4 \%$ of $\mathrm{CHWs}$ reported that they have all the necessary registers and education tools they need for their work, and only $27.2 \%$ of $\mathrm{CHWs}$ reported they that have all the necessary assessment tools.

Overall, CHWs reported they do not have protective materials. As per their mandate, $\mathrm{CHWs}$ were sometimes required to accompany clients to a Health Center. The results show that the average travel time to $\mathrm{HC}$ was 94 minutes. Also, the mean number of households that $\mathrm{CHW}$ is responsible for is 172 households, with $\mathrm{CHWs}$ reporting serving an average of 27 clients per month. About $80 \%$ of $\mathrm{CHWs}$ had over four years of working experience. Only $15.2 \%$ of $\mathrm{CHWs}$ received in-kind payment for their services. $31.8 \%$ of $\mathrm{CHW}$ were members of a local level for profit cooperative. In terms of socioeconomic status, the results show that $6.4 \%$ of the sample are in "Ubudehe" category 1 , whereas $40 \%$ and $56 \%$ are in "Ubudehe" category 2 and "Ubudehe" category 3 , respectively. Also, $22 \%$ of $\mathrm{CHWs}$ were $35 y$ ears or less, while $39 \%$ and $39 \%$ were aged between $36-49$ years and 50 years and above, respectively. All CHWs received basic education with about $23 \%$ of them having more than primary education, while the majority $(77 \%)$ had primary education level. In terms of primary occupation, $95 \%$ of $\mathrm{CHWs}$ are smallholder farmers. $87.4 \%$ of $\mathrm{CHWs}$ were married, and about half of them belonged to households with over seven members.

\section{Bivariate}

Table 2 shows findings from the bivariate analysis. Broadly, some structural and individual-level factors were significantly associated with increased job satisfaction among $\mathrm{CHWs}$. At the structural level our findings show that $\mathrm{CHWs}$ highly performed on the job $(\mathrm{OR}=11.91, \mathrm{p}<0.001)$ or highly motivated $(\mathrm{OR}=15.85, \mathrm{p}<0.001)$, were more likely to have high job satisfaction compared to CHWs poorly performed or with low motivated respectively. Individual supervision ( $\mathrm{OR}=6.53, \mathrm{p}<0.001)$ was associated with higher odds of job satisfaction. $\mathrm{CHWs}$ who received formal training on $\mathrm{CBMNCH}(\mathrm{OR}=2.28, \mathrm{p}<0.001)$ and peer support $(\mathrm{OR}=1.82, \mathrm{p}<0.01)$ had higher odds of reporting high job satisfaction. Lacking assessment tools $(\mathrm{OR}=0.38$, $\mathrm{p}<0.001)$ was associated with lower odds of job satisfaction.

Increased years of experience $(\mathrm{OR}=2.76 \mathrm{p}<0.001)$ were significantly associated with higher odds of job satisfaction. Lacking in-kind payment (OR=0.32, $\mathrm{p}<0.001$ ) was associated with lower odds of job satisfaction. Among the individual-level variables included in the analysis, education was the only significant predictor of job satisfaction: those with more than primary education $(O R=1.69, p<0.01)$ had higher odds of job satisfaction compared to their counterparts with primary education.

\section{Multivariate}

Table 3 shows findings from multivariate analysis. Findings were largely consistent with bivariate results. At the structural level, we found that $\mathrm{CHWs}$ highly motivated $(\mathrm{OR}=8.59, \mathrm{p}<0.001)$ had significantly higher odds of job satisfaction compared to those with low motivation. CHWs highly performed on the job $(\mathrm{OR}=7.08, \mathrm{p}<0.001)$ had significantly higher odds of reporting high job satisfaction compared to CHWs lowly performed. However, CHWS with a high level of knowledge about $\mathrm{CBMNCH}(\mathrm{OR}=0.51, \mathrm{p}<0.05)$ had lower odds of satisfaction compared to their counterparts. CHWs who were supervised once every month $(\mathrm{OR}=6.19, \mathrm{p}<0.001)$ had higher odds of being satisfied compared to those who never received supervision. $\mathrm{CHWs}$ with formal training $(\mathrm{OR}=2.24, \mathrm{p}<0.05)$ had higher odds of being satisfied compared to their counterparts. CHWs who received peer support $(\mathrm{OR}=2.66, \mathrm{p}<0.01)$ had higher odds of being satisfied compared to $\mathrm{CHWs}$ without peer support. CHWs who lacked assessment tools had lower odds $(\mathrm{OR}=0.32(\mathrm{p}<0.05)$ of being satisfied compared to $\mathrm{CHWs}$ with all required tools. CHWs who do not receive in-kind payment for their work performance were more likely to be unsatisfied compared to $\mathrm{CHWs}$ who received inkind payment $(\mathrm{OR}=0.53, \mathrm{p}<0.01)$.

\section{Discussion}

Health workers' job satisfaction plays a key role in the quality of health service delivery. Given the specific responsibilities of CHWs in the context of Rwanda where they fill an important gap in health service delivery, understanding the predictors of their job satisfaction is key in proffering policy solutions for improving the quality of their work. Overall, CHWs satisfaction was found to be significantly associated with mainly structural level factors including level of motivation, role performance, individual supportive supervision, formal training, access to required materials, peer support and in-kind benefits from the community, among others. This finding emphasizes the important role of overarching structural factors in guaranteeing CHWs job satisfaction in the context of Rwanda. However, overall, the results of this study indicate that the proportion of CHWs who are highly satisfied with their work is more than those who may be dissatisfied. These findings were found to be largely consistent with the studies of Ding et al. ${ }^{24}$ and Mpemberi et al. ${ }^{25}$ also emphasize the role of structural factors in guaranteeing the job satisfaction of health workers.

Given the evidence of a link between job satisfaction and performance, researchers often use workers' performance as a proxy to measure their job satisfaction as workers who are high performers also tend to report higher job satisfaction ${ }^{26,27}$. Consistent with this observation and a recent study by Khatri, Mishra, and Khanal ${ }^{28}$, the middle and high performing $\mathrm{CHWs}$ workers in this study had a higher likelihood of reporting job satisfaction compared to $\mathrm{CHWs}$ who reported low performance. Earlier, studies ${ }^{29,30}$ have highlighted a bidirectional relationship between job satisfaction and performance where $11.8 \%$ of health workers' performance was explained by their job satisfaction. In this regard, in evaluating CHWs job satisfaction in Rwanda, stakeholders can achieve this through performance appraisals, and where CHWs performance is seen to be below a set target, appropriate measures can be put in place to address any outstanding issues that may be adversely affecting their job satisfaction. 
Furthermore, the finding that motivation was a significant predictor of CHWs satisfaction may not be too surprising. Specifically, community health workers with middle to high motivation were more likely to belong to a high category of job satisfaction compared to those with poor motivation. This finding is consistent with the current literature's suggests that motivation, whether intrinsic or extrinsic, plays a key role in health workers' job satisfaction ${ }^{25,34-37 .}$ Besides, Lambrou et al. ${ }^{31}$ also found that intrinsic factors measured by internal thought processes and perceptions about motivation, and extrinsic factors measured by monetary rewards and recognition for work done, greatly influenced health workers' job satisfaction. However, CHWs' motivation and its link to their job satisfaction could also be due to the overwhelming community recognition of their work ${ }^{16,33}$. Similar links were revealed by a study conducted by Liverpool School of Tropical Medicine Centre for Maternal and Newborn Health, in collaboration with UNICEF and Rwanda Biomedical Center (RBC), where most CHWs exhibit intrinsic motivation as recruitment into the program was mostly voluntary with no financial compensation. In this regard, only individuals with a desire to help address persistent maternal and child health care challenges in the community opted to be trained and commissioned as officers despite insufficient remunerations ${ }^{32}$. It is therefore imperative for the Rwandan government to effectively harness this high level of motivation to ensure the delivery of high-quality health services in rural communities by $\mathrm{CHWs}$.

The findings further revealed that CHWs with high knowledge about their primary mandate, specifically, maternal, newborn and child health care were less likely to report job satisfaction. Although this finding may seem counter-intuitive, it is possible that CHWs with high knowledge of their mandates and conscious of the important function they serve in the healthcare delivery chain are dissatisfied with some existing inefficiencies impeding their ability to effectively discharge or execute their mandates in reducing maternal and child mortality. Consistent with this observation, Mathauer and Imhoff ${ }^{34}$ have revealed that, where health workers are unable to perform their duties because of bureaucracies and other delays in accessing the necessary tools to perform their duties, they become frustrated and often report job dissatisfaction.

Both quantitative and qualitative literature have discussed the importance of supportive supervision on job satisfaction among health care workers in several contexts ${ }^{38-40}$. According to previous studies, the supervision of community health workers in developing countries is critical to ensure that they perform well, deliver quality services and be motivated ${ }^{41-43}$. Consistent with these scholarships, findings from this study revealed that lack of supervisory support negatively affects $\mathrm{CHWs}$

$w$ or ksatiaction. Thus, CHWswithat $\leq * o \neq \supset p$ or tive $\supseteq$ rvisionamonthwerem or elikely $\rightarrow$ be $\in$ ahighcateg or yofw or ksatiactionco.

decisions and feelings as they perceive their work is valued and appreciated and through this, enhance their greater work satisfaction ${ }^{44}$. In addition to supervision from superiors, Hill et al. ${ }^{38}$ have also emphasized the importance of community and peer supervision for $\mathrm{CHW}$ which was also found to be associated with improved work performance. Earlier studies in Rwanda identified sufficient supervision as a major barrier affecting effective service delivery by $\mathrm{CHWS}^{16}$. Thus, this finding suggests that stakeholders of the $\mathrm{CHWs}$ program might need to pay particular attention to this critical to improving supportive supervision.

In addition to supportive supervision, training of $\mathrm{CHWs}$ before the commencement of their duties and other in-service training is seen as particularly useful in enhancing their knowledge and skills for service provision. Training as an indispensable tool in the work of community health workers is useful in the transfer of useful skills and information for the effective delivery of health services to hard-to-reach populations ${ }^{44,45}$. CHWs, therefore, consider training as an essential component in achieving their mandate as health workers. Among others, CHWs explained that more frequent training improved their efficiency, confidence, and knowledge base as most of them are not originally trained as a health professional. They feel empowered and respected within their respective communities when they receive training from superiors who are active health service professionals with many years of work experience ${ }^{16}$. To this regard, it may not be surprising that in this study $\mathrm{CHWs}$ who received formal training in $\mathrm{CBMNCH}$ were more likely to be in a high category of job satisfaction compared to those who have never received formal training in $\mathrm{CBMNCH}$. Therefore, $\mathrm{CWHs}$ who received limited or no training were less likely to be satisfied with their job given its adverse influence on the effective delivery of their mandates as community volunteers. These findings further suggest that stakeholders in the $\mathrm{CHWs}$ program should focus on making the training of $\mathrm{CHWs}$ more frequent to give them opportunities to improve their knowledge and skills. This will likely lead to better performance of their assigned tasks which could also improve their feeling of accomplishment (satisfaction) from their work.

Furthermore, in the health delivery literature, peer support is a crucial factor in the retention of health workers as they share knowledge and discuss how to surmount challenges in the performance of their daily duties. In this study, peer support, as one of the facets of job satisfaction, was also examined and it was found to be a predictor of job satisfaction for CWHs. CHWs who had good peer support were more likely to be in the high category of job satisfaction compared to their counterparts. These results were consistent with other studies such as Jayasuriya et al. ${ }^{46}$, who found relationships with colleagues and other forms of peer support to be a strong predictor of job satisfaction. Similarly, other scores of scholars ${ }^{47,48}$ from a qualitative enquiry approach have shown inter-personal relationships as an important ingredient in health workers' motivation. This finding is very useful for policy consideration among CHWs stakeholders as they can target strengthening peer support activities as this is currently not implemented in the study context.

Access to working materials and other essentials is necessary for meeting targets and effective discharge of responsibilities for health workers particularly in the context of developing countries. Therefore, although financial rewards are important for motivating, retaining and ensuring health worker satisfaction, the presence of adequate resources in the form of supplies and essentials is very useful in improving the morale and work satisfaction of health workers significantly ${ }^{49}$. In this context, it may not be too surprising for this study revealed that CHWs who had limited access to assessment tools which is important in the discharge of their duties were less likely to report being satisfied with their jobs compared to those that had regular access to these materials. Other studies $^{50,51}$ have reported the same findings. These suggest that it is necessary to sufficiently equip CHWs to perform their work and that in turn could improve their work satisfaction.

While financial rewards and motivation are linked to health worker job satisfaction and retention in many contexts ${ }^{33,42,43}$, in Rwanda, the community health Loading [MathJax]/jax/output/CommonHTML/jax.js ed on little or no remuneration. However, CHWs are encouraged to form cooperatives where they initiate income 
generation activities and profits from these initiates may be used by CHWs as financial compensation for their work. Thus, cooperatives serve as the main source of financial remuneration for $\mathrm{CHWs}$. The findings reveal that $\mathrm{CHWs}$ who perceived their cooperatives to be profitable, implying they may be gaining some financial rewards from their cooperatives were more likely to report job satisfaction compared to those who did not belong to a profitable cooperative. In this regard, it can be argued that although the $\mathrm{CHW}$ program was established voluntarily, financial remuneration may still be playing a key role in $\mathrm{CHWs}$ job satisfaction as reported by earlier studies $25,43,52$. Furthermore, $\mathrm{CHWs}$ who received payment in kind for their services were more likely to have job satisfaction compared to those that were not receiving any payments from community members. Given the voluntary base of services rendered by $\mathrm{CHWs}$ to their community, payments in kind make $\mathrm{CHWs}$ feel appreciated for their work, explaining why they are more likely to have better job satisfaction ${ }^{16,34}$. Based on these findings, it may be critical for stakeholders of the CHW program in Rwanda to rethink how they can provide a suitable financial incentive to CHWs to engender strong feelings of governmental support and in turn, better job satisfaction.

In general, work satisfaction revolves around feelings and attitudes that an individual has with regards to their work that motivates them to fulfil an anticipated target or achievement ${ }^{52}$. Given the multiplicity of factors that are associated with health workers' job satisfaction, this study argues that in the context of Rwanda, CHWs can be satisfied with some aspects of their job and the same time remain dissatisfied with other aspects that fail to meet their expectations. Therefore, this study suggests a holistic approach in considering all the possible factors associated with work satisfaction of CHWs.

Whilst this study provides greater insights into the $\mathrm{CHWs}$ ' job satisfaction in the provision of $\mathrm{CBMNCH}$ services for timely access to $\mathrm{MNCH}$ in rural communities Rwanda, there are some limitations. First, the study was conducted in high need districts, making it difficult to extrapolate the finding to the rest of the country. Second, given that respondents were asked to recall most of the responses, some of the responses may be subject to recall bias which may influence the reliability of the collected data. However, the likelihood of recall bias was reduced by reducing the recall period to a maximum of 12 months. Lastly, given the cross-sectional nature of this data, findings are only restricted to statistical associations and therefore, causal-effect could not be inferred.

\title{
Conclusion
}

The findings of this study provide in-depth insight into the current job satisfaction of CHWs in the provision of $\mathrm{CBMNCH}$ in rural communities, Rwanda. The findings indicated that there a high need for the managers of $\mathrm{CHW}$ programs and other stakeholders to improve the working conditions of $\mathrm{CHWs}$ to enhance their job satisfaction, to enable effective provision of $\mathrm{CBMNCH}$. This study was conducted before the intervention of the TSAM project in the study areas. Therefore, it would be useful to do a post-intervention analysis to do a comparative study examining the impact of TSAM intervention on job satisfaction of $\mathrm{CHWs}$ regarding the provision of $\mathrm{CBMNCH}$ in Rwanda.

\section{Abbreviations}

\author{
$\mathrm{CBMNCH}$ \\ Community Based Maternal, Neonatal, and Child Healthcare \\ CHW \\ Community Health Worker \\ $\mathrm{HC}$ \\ Health Center \\ $\mathrm{MNCH}$ \\ Maternal, Neonatal, and Child Health \\ ORs \\ Odd Ratios \\ RBC \\ Rwanda Biomedical Center \\ SMS \\ Short Message Service \\ TSAM \\ Training, Support, and Access Model \\ UNICEF \\ United Nations Children's Fund \\ UR \\ University of Rwanda \\ UWO \\ University of Western Ontario \\ WHO \\ World Health Organization
}

\section{Declarations}

\section{Ethics approval and consent to participate}


Ethical approval for the study was obtained from both the Research Ethics Board at the University of Western Ontario, Canada, and the College of Medicine and Health Sciences Institutional Review Board (IRB), at the University of Rwanda. The authorization to conduct the study locally was granted through the districts` administrative authorities. Before the study, informed written consent was obtained from CHWs with the option to withdraw at any time during the study.

\section{Consent for publication}

Not applicable

\section{Availability of data and materials}

The datasets used and/or analyzed during the current study are available from the corresponding author on reasonable request.

\section{Competing interests}

The authors declare that they have no competing interests

\section{Funding}

The Training, Support, and Access Model (TSAM) project provided the fund regarding only logistic issues to facilitated fieldwork activities (data collection). There was no funding body in the design of the study, analysis, interpretation of data and writing the manuscript.

\section{Authors' contributions}

All authors designed the full protocol of the study. JBB collected, analyzed, and interpreted data and wrote the manuscript. IL read and approved the final manuscript

\section{Acknowledgements}

The authors would also like to extend his gratitude to the TSAM project, especially Professor David Cechetto, who agreed to provide funds for the logistic issue to perform fieldwork activities. The authors would also like to give thanks to the Community Health Workers who participated in this study and sharing the experiences and the time dedicated to this research.

\section{Tables}




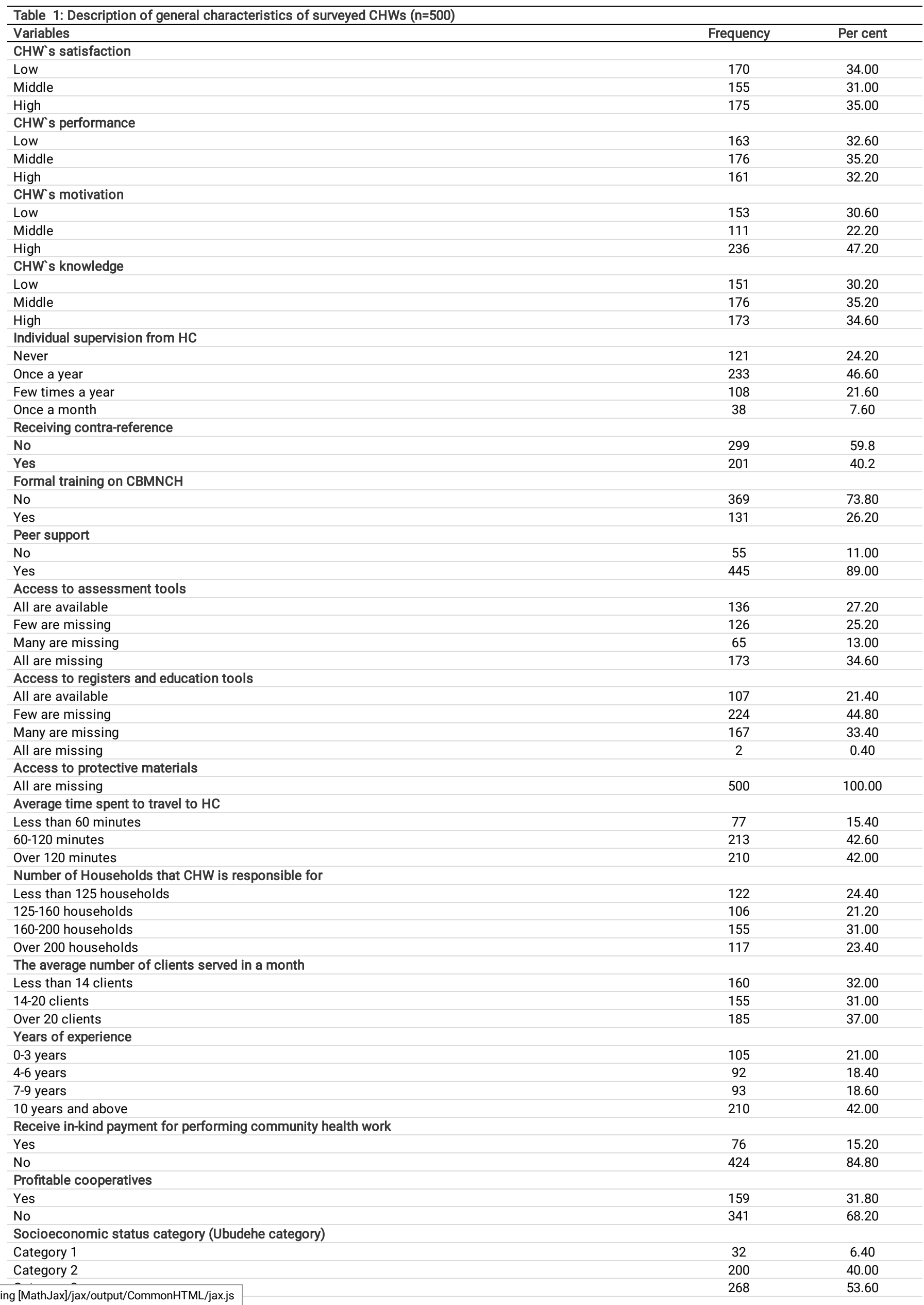


Age in years

35 years old and below 22.20

50 years old and above 38.60

Marital status

Married

Others

Education

Primary education

$437 \quad 87.40$

More than primary education 22.60

Occupation

Nonprofessional Farming

Other

$476 \quad 95.20$

CHW's Household size

Less than 5 members

$24 \quad 4.80$

5-6 members

108

21.60

7-8 members

26.60

Over 8 members

124

Table 2: Estimates for bivariate ordered logistic regression predicting the variability of $\mathrm{CHWs}^{`}$ job satisfaction in service provision of $\mathrm{CBMNCH}$ ( $\mathrm{n}=500$ ) Variables

Bivariate

CHW's performance

OR(SE)

Low

1.00

Middle

$7.10(1.52)^{\star \star \star}$

High

$11.91(2.80)^{\star \star \star}$

CHW's motivation

Low

Middle

High

1.00

CHW's knowledge

$5.80(1.48)^{\star \star \star}$

Low

$15.82(3.74)^{\star * *}$

Middle

1.00

High

$1.20(0.23)$

Individual supervision from $\mathrm{HC}$

Never

$0.84(0.17)$

Once a year

1.00

Few times a year

$1.28(0.26)$

Once a month

$1.31(0.32)$

Formal training on $\mathrm{CBMNCH}$

No

$6.53(2.18))^{\star \star \star}$

Yes

1.00

Peer support

No

$28(0.43)^{\star \star \star}$

Yes

1.00

Access to assessment tools

$1.82(0.40)^{\star \star}$

All are available

Few are missing

1.00

Many are missing

$1.04(0.22)$

$0.58(0.19)$

All are missing

$0.38(0.09)^{\star \star \star}$

Access to registers and education tools

All are available

1.00

Few are missing

$\frac{1.92(0.43)^{\star \star}}{2.23(0.52)^{\star \star}}$

Many are missing

All are missing

$0.64(0.62)^{\star \star \star}$

Average time spent to travel to $\mathrm{HC}$

Less than 60 minutes

1.00

60-120 minutes

$1.33(0.33)$

Over 120 minutes

$1.47(0.36)$

Number of Households that $\mathrm{CHW}$ is responsible for

Less than 125 households

1.00

125-160 households

$0.77(0.17)$

160-200 households

$0.92(0.20)$

Over 200 households

$0.85(0.19)$

The average number of clients served in a month

Less than 14 clients 
Over 20 clients

$0.83(0.16)$

Years of experience

$0-3$ years

4-6 years

1.00

7-9 years

$41(0.59)^{* * \star}$

10 years and above

$2.63(0.70)^{\star \star \star}$

Receive in-kind payment for performing community health work

Yes

$2.76(0.61)^{\star \star \star}$

No

1.00

Profitable cooperatives

Yes

No

$32(0.07)^{\star \star \star}$

Socioeconomic status category (Ubudehe category)

Category 1

Category 2

Category 3

Age in years

35 years old and below

1.00

$1.29(0.22)$

36-49 years old

50 years old and above

1.00

$0.84(0.30)$

$0.79(0.28)$

Marital status

Married

Others

1.00

$1.16(0.22)$

2.62(0.86)

Education

Primary education

1.00

More than primary education

$10.05(0.25)$

Occupation

Nonprofessional Farming

1.00

Other

CHW's Household size

Less than 5 members

5-7 members

8 members and above

$0.87(0.16)$

$0.61(0.20)$

$0.61(0.21)$

)

Standard errors in parentheses

${ }^{*} p<0.05,{ }^{* \star} p<0.01,{ }^{* \star *} p<0.001$ 


\section{Variables}

Model 1

OR(SE)

Model 2

CHW's performance

Low

Middle

1.00

OR(SE)

High

CHW's motivation

Low

Middle

High

CHW's knowledge

Low

Middle

High

Individual supervision from HC

Never

Once a year

Few times a year

Once a month

Formal training on $\mathrm{CBMNCH}$

No

Yes

Peer support

No

$4.23(1.16)^{\star \star *}$

$7.82(2.11)^{\star \star \star}$

1.00

1.00

$4.06(1.14)^{\star \star \star}$

$7.08(2.00)^{\star \star \star}$

Yes

$3.67(1.13)^{* * *}$

$8.41(2.39)^{\star \star \star}$

$\frac{1.00}{3.70(1.14)^{\star \star \star}}$

1.00

$0.83(0.21)$

$0.55(0.15)^{*}$

$8.59(2.45)^{\star \star \star}$

Access to assessment tools

All are available

Few are missing

Many are missing

All are missing

Access to registers and education tools

All are available

Few are missing

Many are missing

All are missing

Average time spent to travel to $\mathrm{HC}$

Less than 60 minutes

60-120 minutes

1.00

$1.17(0.31)$

$1.15(0.38)$

$6.71(3.31)^{\star \star \star}$

1.00

$0.78(0.20)$

$0.51(0.15)^{\star}$

Over 120 minutes

Number of Households that $\mathrm{CHW}$ is responsible for

Less than 125 households

$1.00 \quad 1.00$

$2.17(0.75)^{*}$

$2.24(0.82)^{\star}$

125-160 households

160-200 households

Over 200 households

1.00

1.00

$2.72(0.96)^{\star \star}$

$2.66(1.00)^{\star \star}$

The average number of clients served in a month

Less than 14 clients

14-20 clients

Over 20 clients

1.00

$0.85(0.26)$

$0.37(0.15)^{*}$

$0.35(0.10)^{\star * \star}$

1.00

$1.24(0.35)$

$1.25(0.43)$

$6.19(3.06)^{\star \star \star}$

Years of experience

$0-3$ years

4-6 years

7-9 years

10 years and above

Receive in-kind payment for performing community health work

Yes

$\begin{array}{cc}1.00 & 1.00 \\ 2.13(0.63)^{\star \star} & 2.27(0.69)^{\star \star} \\ 2.36(0.77)^{\star \star} & 2.63(0.89)^{\star \star} \\ 4.08(2.63)^{\star \star \star} & 5.75(4.96)^{\star \star \star}\end{array}$

No

1.00

1.00

$1.13(0.35)$

$1.23(0.40)$

$1.57(0.48)$

1.68(0.53)

Profitable cooperatives

Unprofitable

1.00

1.00

$0.89(0.27)$

$0.95(0.29)$

$1.29(0.36)$

$1.32(0.38)$

0.72(0.23)

$0.660 .22)$

profitable

Socioeconomic status category (Ubudehe category)

Category 1

Category 2

1.00

1.00

1.19(0.32)

$1.11(0.30)$

0.91(0.23)

$0.87(0.23)$

Category 3

Age in years

35 years old and below

$\begin{array}{ll}1.00 & 1.00\end{array}$

$0.98(0.38)$

$1.04(0.42)$

$0.75(0.33)$

$0.83(0.37)$

$0.78(0.32)$

$0.87(0.38)$

36-49 years old

$\begin{array}{cc}1.00 & 1.00 \\ 0.56(0.18)^{*} & 0.53(0.17)^{*}\end{array}$

50 years old and above

$.53(0.17)^{*}$

Marital status

Loading [MathJax]/jax/output/CommonHTML/jax.js

$\begin{array}{cc}1.00 & 1.00 \\ 1.80(0.43)^{*} & 1.83(0.45)^{*} \\ & 1.00 \\ & 0.89(0.37) \\ & 0.68(0.28)\end{array}$

1.00

$0.71(0.22)$

1.88(0.88) 


\section{Education}

Primary education

More than primary education

Occupation

Nonprofessional Farming

Other

CHW's Household size

Less than 5 members

5-7 members

1.00

8 members and above

1.00

$1.38(0.33)$

1.00

$0.56(0.26)$

1.00

$1.16(0.30)$

$0.76(0.35)$

\begin{tabular}{|c|c|c|}
\hline Log pseudo-likelihood & -388.54599 & -382.3989 \\
\hline Wald X2 & 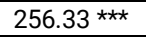 & $260.73 * \star \star$ \\
\hline Pseudo R2 & 0.2918 & 0.3030 \\
\hline$N$ & 500 & 500 \\
\hline
\end{tabular}

Standard errors in parentheses

${ }^{\star} p<0.05,{ }^{* \star} p<0.01,{ }^{\star \star \star} p<0.001$

\section{References}

1. WHO, UNICEF. UNFPA WBG and U estimates. Trends in Maternal Mortality: 1990 to 2015: Estimates by WHO, UNICEF, UNFPA, World Bank Group and the United Nations Population Division. Geneva: World Health Organization; 2015.; 2015.

https://www.who.int/reproductivehealth/publications/monitoring/maternal-mortality-2015/en/.

2. Who. The World Health Report HEALTH SYSTEMS FINANCING The Path to Iniversal Coverage.; 2010. https://www.who.int/whr/2010/en/.

3. Glenton C, Colvin CJ, Carlsen B, et al. Barriers and facilitators to the implementation of lay health worker programmes to improve access to maternal and child health: Qualitative evidence synthesis. Cochrane Libr Cochrane Database Syst Rev. 2013;2013(10). doi:10.1002/14651858.CD010414.pub2.

4. World Health Organization (WHO). Health Workforce Requirements for Universal Health Coverage and the Sustainable Development Goals.; 2016. https://apps.who.int/iris/bitstream/handle/10665/250330/9789241511407-eng.pdf.

5. Glenton C, Javadi D. Community Health Worker Roles and Tasks. Published online 2012:1-15. https://www.mchip.net/sites/default/files/mchipfiles/07_CHW_Tasks.pdf.

6. Neal S, Channon A, Carter S, Falkingham J. Universal health care and equity: evidence of maternal health based on an analysis of demographic and household survey data. Int J Equity Health. 2015;14(56). doi:10.1186/s12939-015-0184-9.

7. WHO, The World Bank. Tracking Universal Health Coverage: 2017 Global Monitoring Report:; 2017. https://www.who.int/publications/almaata_declaration_en.pdf\%0Ahttp://www.who.int/gender-equity-rights/knowledge/anchoringuhc.pdf\%0Ahttp://apps.who.int/iris/bitstream/handle/10665/259817/9789241513555-eng.pdf;jsessionid=C29E21005A5692511BE2B70BD2D3C941?se.

8. Rao M, Pilot E. The missing link - the role of primary care in global health. Glob Health Action. 2014;7(SUPP.1):1-6. doi:10.3402/gha.v7.23693.

9. Kok MC, Broerse JEW, Theobald S, Ormel H, Dieleman M, Taegtmeyer M. Performance of community health workers: Situating their intermediary position within complex adaptive health systems. Hum Resour Health. 2017;15(1):1-8. doi:10.1186/s12960-017-0234-z.

10. LeFevre AE, Mpembeni R, Chitama D, et al. Profile, knowledge, and work patterns of a cadre of maternal, newborn, and child health CHWs focusing on preventive and promotive services in Morogoro Region, Tanzania. Hum Resour Health. 2015;13(98):1-14. doi:10.1186/s12960-015-0086-3.

11. Kassebaum NJ, Bertozzi-Villa A, Coggeshall MS, et al. Global, regional, and national levels and causes of maternal mortality during 1990-2013: A systematic analysis for the Global Burden of Disease Study 2013. Lancet. 2014;384(9947):980-1004. doi:10.1016/S0140-6736(14)60696-6.

12. Requejo JH, Bhutta ZA. The post-2015 agenda: staying the course in maternal and child survival. Arch Dis Child. 2015;100(Suppl 1):76-81. doi:10.1136/archdischild-2013-305737.

13. Rwanda Ministry of Health. Health Sector Annual Report July. 2015-June 2016; 2016. http://www.moh.gov.rw/fileadmin/templates/MOHReports/Health_20Sector_20Annual_20Report_202015-2016_25082016.pdf.

14. MINISTRY OF HEALTH OF RWANDA. National Community Health Strategic Plan July2013-June2018.; 2013. http://moh.gov.rw/fileadmin/templates/CHD_Docs/CHD-Strategic_plan.pdf.

15. National Institute of Statistics of Rwanda. Rwanda Demographic and Health Survey, 2014-2015.; 2014. http://www.statistics.gov.rw/publication/demographic-and-health-survey-20142015-final-report.

16. Condo J, Mugeni C, Naughton B, et al. Rwanda's evolving community health worker system: a qualitative assessment of client and provider perspectives. Hum Resour Health. 2014;12(1):71. doi:10.1186/1478-4491-12-71.

17. Rwanda Ministry of Health. National Community Health Policy.; 2015. http://www.moh.gov.rw/fileadmin/templates/policies/NATIONAL_COMMUNITY_HEALTH_POLICY.pdf.

18. TSAM. Project Implementation Plan Training, Support and Access Model (TSAM) for Maternal, Newborn and Child Health (MNCH) in Rwanda and Burundi;; 2016. https://owl.uwo.ca/portal/site/9e17d319-0b4c-45cf-9e4f-051d5ff86619/tool/71900ee6-6f6e-44c8-98b1-5faa02d8c111/ShowPage? returnView=\&studentltemld=0\&backPath=\&errorMessage=\&clearAttr=\&source=\&title=\&sendingPage=64460931\&newTopLevel=false\&postedComment=fa 
19. Kothari CRC. Research Methodology Methods \& Techniques. Second Rev. New Age International; 2004.

http://dl.saintgits.org/xmlui/bitstream/handle/123456789/1133/Research Methodology C R Kothari \%28Eng\%29 1.81 MB.pdf?sequence = 1\&isAllowed = y.

20. Kumar R, Ahmed J, Shaikh BT, Hafeez R, Hafeez A. Job satisfaction among public health professionals working in public sector: A cross sectional study from Pakistan. Hum Resour Health. 2013;11(2):1. doi:10.1186/1478-4491-11-2.

21. Blaauw D, Ditlopo P, Maseko F, et al. Comparing the job satisfaction and intention to leave of different categories of health workers in Tanzania, Malawi, and South Africa. Glob Health Action. 2013;6(1):19287. doi:10.3402/gha.v6i0.19287.

22. Bello S, Dt A, Mc A. COMMUNITY MEDICINE AND PRIMARY HEALTH CARE. Determinants of Job Satisfaction among Physicians in Public Hospitals in Calabar, Nigeria Keywords. J Community Med Prim Heal Care. 2018;30(1):19-33. https://www.ajol.info/index.php/jcmphc/article/view/168630.

23. Dushimimana M-A. Ubudehe categories to be reviewed. The New Times. https://www.newtimes.co.rw/news/ubudehe-categories-be-reviewed. Published 2019.

24. $10.1371 /$ journal.pone. 0073438

Ding H, Sun X, Chang W, wei, Zhang L, Xu X ping. A Comparison of Job Satisfaction of Community Health Workers before and after Local Comprehensive Medical Care Reform: A Typical Field Investigation in Central China. PLoS One. 2013;8(9):e73438. doi:10.1371/journal.pone.0073438.

25. Mpembeni RNM, Bhatnagar A, LeFevre A, et al. Motivation and satisfaction among community health workers in Morogoro Region, Tanzania: Nuanced needs and varied ambitions. Hum Resour Health. 2015;13(1):1-10. doi:10.1186/s12960-015-0035-1.

26. Böckerman P, Ilmakunnas P. The job satisfaction-productivity nexus: A study using matched survey and register data. Ind Labor Relations Rev. 2012;65(2):244-62. doi:10.1177/001979391206500203.

27. Christen M, lyer G, Soberman D. Job satisfaction, job performance, and effort: A reexamination using agency theory. J Mark. 2006;70(1):137-50. doi:10.1509/jmkg.2006.70.1.137.

28. Khatri RB, Mishra SR, Khanal V. Female Community Health Volunteers in Community-Based Health Programs of Nepal: Future Perspective. Front Public Heal. 2017;5(181). doi:10.3389/fpubh.2017.00181.

29. Aisha Naseer K, Perveen M, Afzal, Ali Waqas PDSAG. The Impact of Leadership Styles on Staff Nurses' Turnover Intentions. Saudi J Med Pharm Sci. 2017;3(10B):1133-8. doi:10.21276/sjmps.2017.3.10.20.

30. Albagawi B. Leadership Styles of Nurse Managers and Job Satisfaction of Staff Nurses: Correlational Design Study. Eur Sci J ESJ. 2019;15(3):254-75. doi:10.19044/esj.2019.v15n3p254.

31. Lambrou P, Kontodimopoulos N, Niakas D. Motivation and job satisfaction among medical and nursing staff in a Cyprus public general hospital. Hum Resour Health. 2010;8(26):1-9. doi:10.1186/1478-4491-8-26.

32. Liverpool School of Tropical Medicine Centre for Maternal and Newborn Health, UNICEF and RBC. Comprehensive External Evaluation of the Community Health Program in Rwanda.; 2016. https://www.unicef.org/evaldatabase/files/Annex_5_Survey_Report.pdf.

33. Li L, Hu H, Zhou H, et al. Work stress, work motivation and their effects on job satisfaction in community health workers: A cross-sectional survey in China. BMJ Open. 2014;4(e004897). doi:10.1136/bmjopen-2014-004897.

34. Mathauer I, Imhoff I. Health worker motivation in Africa: The role of non-financial incentives and human resource management tools. Hum Resour Health. 2006;4(24):1-17. doi:10.1186/1478-4491-4-24.

35. Gopalan SS, Mohanty S, Das A. Assessing community health workers' performance motivation: A mixed-methods approach on India's Accredited Social Health Activists (ASHA) programme. BMJ Open. 2012;2(e001557). doi:10.1136/bmjopen-2012-001557.

36. Ge C, Fu J, Chang Y, Wang L. Factors associated with job satisfaction among Chinese community health workers: A cross-sectional study. BMC Public Health. 2011;11(884). doi:10.1186/1471-2458-11-884.

37. Ndangurura D. Assessment of commu nity health workers incentives on maternal and newborn health services performance. Published online 2015. https://www.memoireonline.com/09/15/9278/Assessment-of-community-health-workers-incentives-on-maternal-and-newborn-health-servicesperformanc.html.

38. Hill Z, Dumbaugh M, Benton L, et al. Supervising community health workers in low-income countries - a review of impact and implementation issues. Glob Health Action. 2014;7(1):24085. doi:10.3402/gha.v7.24085.

39. PEER SUPPORT AROUND THE WORLD Supervision of Community Health Workers in LowVu H. ACCELERATING BEST PRACTICES IN. PEER SUPPORT AROUND THE WORLD Supervision of Community Health Workers in Low- and MiddleIncome Countries Gold-standards for CHW supervision Innovative approaches to CHW supervision. Peers for Progress. Published 2019. Accessed July 1, 2018. http://peersforprogress.org/pfp_blog/supervision-of-community-health-workers-in-low-and-middle-income-countries/.

40. Roberton T, Applegate J, Lefevre AE, et al. Initial experiences and innovations in supervising community health workers for maternal, newborn, and child health in Morogoro region, Tanzania. Hum Resour Health. 2015;13(1):1-12. doi:10.1186/s12960-015-0010-x.

41. Manongi RN, Marchant TC, Bygbjerg IC. Improving motivation among primary health care workers in Tanzania: A health worker perspective. Hum Resour Health. 2006;4:1-7. doi:10.1186/1478-4491-4-6.

42. Bempah BSO. Determinants of Job Satisfaction among Community Health Workers in the Volta Region of Ghana. Public Policy Adm Res. 2013;3(11):111. https://www.iiste.org/Journals/index.php/PPAR/article/view/8740.

43. Tran BX, Van Hoang M, Nguyen HD. Factors associated with job satisfaction among commune health workers: implications for human resource policies. Glob Health Action. 2013;6(1):18619. doi:10.3402/gha.v6i0.18619.

Loading [MathJax]/jax/output/CommonHTML/jax.js 
44. Javanparast S, Baum F, Labonte R, Sanders D, Rajabi Z, Heidari G. The experience of community health workers training in Iran: A qualitative study. BMC Health Serv Res. 2012;12(291):1. doi:10.1186/1472-6963-12-291.

45. O'Donovan J, O'Donovan C, Kuhn I, Sachs SE, Winters N. Ongoing training of community health workers in low-income and middle-income countries: A systematic scoping review of the literature. BMJ Open. 2018;8(4):e021467. doi:10.1136/bmjopen-2017-021467.

46. Jayasuriya R, Whittaker M, Halim G, Matineau T. Rural health workers and their work environment: The role of inter-personal factors on job satisfaction of nurses in rural Papua New Guinea. BMC Health Serv Res. 2012;12(156). doi:10.1186/1472-6963-12-156.

47. Jaskiewicz W, Tulenko K. Increasing community health worker productivity and effectiveness: A review of the influence of the work environment. Hum Resour Health. 2012;10:1-9. doi:10.1186/1478-4491-10-38.

48. Geldsetzer P, Vaikath M, de Neve JW, Bärnighausen T, Bossert TJ. A qualitative and quantitative performance evaluation of Swaziland's Rural Health Motivator program. F1000Research. 2017;6(0):1-20. doi:10.12688/f1000research.11361.1.

49. Sato M, Maufi D, Mwingira UJ, Leshabari MT, Ohnishi M, Honda S. Correction: Measuring three aspects of motivation among health workers at primary level health facilities in rural Tanzania (PLoS ONE (2017) 12:5 (e0176973) DOI: 10.1371/journal.pone.0176973). PLoS One. 2017;12(9):1-17. doi:10.1371/journal.pone.0184599.

50. Ayamolowo SJ. Job Satisfaction and Work Environment of Primary Health Care Nurses in Ekiti State, Nigeria: an Exploratory Study. Int J Caring Sci. 2013;6(3):531-542. https://www.semanticscholar.org/paper/Job-Satisfaction-and-Work-Environment-of-Primary-in-IfeIrinoye/b0c2ef2f534511d4fb010db38d763a24e2d47f97.

51. Zhang M, Yang R, Wang W, Gillespie J, Clarke S, Yan F. Job satisfaction of urban community health workers after the 2009 healthcare reform in China: A systematic review. Int J Qual Heal Care. 2016;28(1):14-21. doi:10.1093/intqhc/mzv111.

52. Ali W. Understanding the Concept of Job Satisfaction, Measurements, Theories and its Significance in the Recent Organizational Environment: A Theoretical Framework. Arch Bus Res. 2016;4(1):100-11. doi:10.14738/abr.41.1735. 